\title{
Curriculum Analytics: Application of Social Network Analysis for Improving Strategic Curriculum Decision-Making in a Research- Intensive University
}

\section{ABSTRACT}

This paper provides insight into the use of curriculum analytics to enhance learning-centred curricula in diverse higher education contexts. Engagement in evidence-based practice to evaluate and monitor curricula is vital to the success and sustainability of efforts to reform undergraduate and graduate programs. Emerging technology-enabled inquiry methods have enormous potential to inform evidence-based practice in complex curriculum settings. For example, curriculum analytics, including data from student learning outcomes, graduate qualities, course selection and assessment activities, can be mined from various student learning systems and analysed to inform curriculum renewal strategies and demonstrate impact at both the program and course level. Curriculum analytics can serve to foster a culture of inquiry and scholarship regarding program improvements that is characterised by information sharing within and across disciplinary borders. This paper presents an innovative technology that draws on social network methodologies for assessing and visualising the integration and linkages across individual courses that ultimately form a student's complete program of study. Insights are grounded in the literature and curriculum leadership experiences in a Canadian research-intensive university setting.

\section{KEYWORDS}

curriculum analytics, curriculum design, learning analytics, scholarship of teaching and learning, educational leadership, social network analysis

\section{INTRODUCTION}

The higher education sector internationally is in the midst of rapid change due in part to pressures evolving from a global competitive market, government accountability and calls for increased undergraduate completion rates (Bernhard, 2012; Hubball, Pearson, \& Clarke, 2013). As noted by Marginson (2008) a nation's economic and social prosperity is now intricately linked to the quality of education undertaken and the percentage of the population completing a higher degree. This reliance on the education system to develop a globally competitive workforce has sparked renewed interest in establishing 
benchmarks and measures of quality for higher education programs, teaching practice and the overall student learning experience (Coates, 2005; Hubball \& Burt, 2004). For example, within the Australian higher education system, the Australian Quality Framework and Tertiary Education Quality and Standards Agency (TEQSA) work to assess and monitor the overall teaching performance of a University (Marshall, Orrell, Cameron, Bosanquet, \& Thomas, 2011). Within Canada, the Ontario Universities Council introduced the quality assurance framework to measure education performance with the goal of fostering incremental improvement (Skolnick, 2010). Broadly speaking, the higher education sector quality assurance systems and frameworks commonly include measures such as course and instructor evaluations, level of qualification of the instructor, and retention and completion rates. This strategic assessment process is largely intended as a broad brush stroke to identify areas for improving curriculum delivery (Hubball \& Burt, 2004) and to facilitate the generation of consistent data to enable institutional benchmarking and peer comparisons.

Although governments, institutions, and industry regulators have an increasing investment in the quality of learning experiences of graduates, traditional curriculum practices (including the delivery model, content and assessment) have predominantly resided with individual academic staff. Arguably the professional disciplines such as Dentistry, Engineering, Law, Medicine, Pharmaceutical Sciences, and Teacher Education can be seen as distinct in their reporting of accredited curriculum practices in comparison to the liberal Arts and Science programs. While the professions tend to have an increased expectancy for documenting learning-centred curriculum processes, evidence-based practices including the pedagogical relationships within and across individual courses remain complex and often poorly communicated or effectively integrated at the program-level (Fraser, 2006; Pearson \& Hubball, 2012). This is often evidenced through curriculum overlap such as the replication of content and an over-emphasis on common assessment types and learning activities (Jessop, McNab, \& Gubby, 2012). While this can be overcome through shared discussions and documentation of practice, such curriculum based conversations are all too infrequent and often clouded by multiple interpretations and definitions of the term (Fraser, 2006). The promotion of an evidence-based practice infused with opportunities for shared communication about strategic learning-centred curriculum processes can provide a holistic analysis of an entire program of study. This is an essential step in order to generate a scalable and cohesive shift in the higher education culture to enhance learning-centred curricula and program reform.

In this context, technology-enabled inquiry methods have enormous potential to inform evidence-based practice in complex curriculum settings. For instance, the field of learning analytics provides the necessary methods, technologies and processes for analysing, interpreting and communicating the results of curriculum-based evaluations and therefore inform the strategic allocation of resources and potential reforms (Wagner \& Ice, 2012). In essence, through the use of technology these curriculum-centric analytics can capture and communicate the complex, situated, and dynamic nature of curriculum practice. This is achieved through the extraction and analysis of data such as student demographics, academic achievement, assessment types, learning outcomes, and implemented learning activities alongside the offshoot of data from student interactions with the institution's suite of learning technologies. This process of data extraction and analysis affords curriculum communities an opportunity to identify the patterns and trends that 
ultimately inform the impact of curriculum practice, as well as strategic visioning for curriculum renewal (Bryk, Gomez, Grunow, \& Bryk, 2011; Friedman, 2008).

This paper discusses a case study of one institution's development and implementation of a curriculum analytics tool designed to identify and visualise the complex learning connections that exist between courses. A specific example is provided to demonstrate the connection between the curriculum network visualisations and the analysis of student graduation rates. Through this example, we discuss the emerging potential of curriculum analytics, drawing on social network analysis (SNA) as a methodology, for visualizing learning-centred curriculum networks that are established through stated pre-requisites and student enrolment (i.e. course selection and progression). The establishment of a curriculum network provides the potential to map, analyse and visualize individual student learning pathways as they progress through a program. As such, there is an opportunity to report on the diversity of assessment undertaken, as well as learning outcomes and experiences encountered by an individual student on their degree pathway. Furthermore, by aggregating and analysing these large historical data sets, effective, efficient, and transparent quality assurance steps can be established regarding integrated learning experiences, student learning outcomes, and evidence-based approaches to curriculum renewal.

\section{CONTEXT}

The University of British Columbia (UBC) is a research-intensive university educating a student population of approximately 50,000. The University offers degree programs through 12 Faculties, 1 College, and 14 Schools (http://www.ubc.ca/). UBC's Place \& Promise visioning document emphasizes the priorities and goals for enhancing the quality of teaching and learning across the institution. In particular, the university's aim is to be known as an institution where "leading edge teaching and learning practices prevail across the University, creating an exceptional learning environment to which students, staff, faculty, and alumni are drawn from all over the globe" (The University of British Columbia, 2012, p.3). The University plan also states goals and actions related to its commitments, including a review and revision of "curricula and pedagogy to ensure that they are informed by leading edge research and research on how people learn" (The University of British Columbia, 2012, p.11).

To meet these aspirational aims, an institution-wide curriculum renewal and scholarship initiative was established focusing on scholarly approaches to curriculum renewal within and across the disciplines, at both undergraduate and graduate levels. Initially, this undertaking began with a comprehensive environmental scan of curriculum practices in order to identify: current course and program goals and areas for development, the potential innovations and challenges associated with curriculum reform, and the support structures and resources necessary to enhance scholarly approaches to curriculum renewal. Hubball and Burt's (2004) conceptual framework for developing, implementing, and evaluating learning-centered curricula in higher education contexts was used to gather and analyze data from the Faculties and Colleges.

Through the environmental scan it was identified that the two most common trends impeding curriculum reform related to the lack of accessible Scholarship of Teaching and Learning (SoTL) expertise and the limited amount of time that could be allocated for developing and evaluating learning-centred curriculum practices (Hubball, Lamberson, \& Kindler, 2012). The needs assessment process revealed that Faculty-level curriculum lead- 
ers had major challenges in accessing the necessary expertise to facilitate and promote evidence-based curriculum reform and establish shared definitions and understanding of curriculum practice. This finding resonates with the work O'Neill (2010), who also noted the dearth of resources and expertise that can readily assist faculty in commencing curriculum work.

It is unsurprising why many faculty consider curriculum change and renewal such an exhaustive and daunting process. However, the adoption of an analytics-based approach that can harvest curriculum data for evaluation and interpretation may provide an effective alternate approach to the more commonly recognized process and product models (Neary, 2003). The implementation of an analytics-centric model can enable a more accessible data-informed assessment of curriculum practice within the institution regardless of size and scope. It was envisaged that through the development of such an analytics process, the time investment necessary among curriculum leaders would be effectively reduced as well as providing clear pathways for orienting discussions surrounding curriculum improvement.

\section{THEORETICAL UNDERPINNINGS: CURRICULUM ANALYTICS}

This section provides a brief overview of the field of learning analytics leading to a more focused discussion of the data and analytics associated with complex, multifaceted, and situated course-level and program-level curriculum practices. Learning analytics research and practice has its roots in technology-enabled inquiry methods that serve evidence-based decision making. (Ferguson, 2012; Wagner \& Ice, 2012). Learning analytics draws on a diversity of research fields and methodologies such as data mining, social network analysis, data visualization, machine learning, learning sciences, psychology, semantics, artificial intelligence, e-learning, and educational theory and practice (Ferguson, 2012). The first International Conference for Learning Analytics held in Banff, Canada (2011), defined learning analytics as the measurement, collection, analysis and reporting of data about learners and their contexts, for the purposes of understanding and optimizing learning and the environments in which it occurs (Siemens \& Baker, 2012). In essence, the student data evolving from interactions with educational technologies alongside demographic and performance data are commonly used to identify behavioural patterns to determine the impact of learning activities and student learning progression (Duval, 2011). For instance, as a student engages with a technology such as the learning management system (LMS) (e.g. BlackBoard, Moodle, Desire2Learn) their interactions are automatically captured and stored. This data can be analysed to provide greater insight into a student's learning progression (Dawson, Macfadyen, \& Lockyer, 2009), social capital, sense of community, and overall satisfaction (Dawson, 2010).

Although the field of learning analytics is rapidly growing, the majority of education institutions are yet to fully capitalize on the available data and analytical resources (Norris, Baer, Leonard, Pugliese, \& Lefrere, 2008). As such, the priorities and questions driving any analyses have tended to be related to the early identification of students at risk of failure (Greller \& Drachsler, 2012). For example, the Purdue University course signals project ${ }^{1}$ is a well-recognized example of early warning systems. The Signals software incorporates student past academic performance and demographics with LMS activity to provide a statistical assessment of an individual learner's probability for success (Arnold, 2010). Similarly, Macfadyen and Dawson (2010) investigated tool use within 
an institutional LMS in order to predict student academic performance. The authors concluded that social learning (discussion forum activity) and formative assessment tasks completed accounted for greater than 30 percent of the variation in student grade. As learning analytics continues to mature as a research field, the depth and scope of analyses undertaken and the development of analytics tools available will have greater impact across the institutions' organizational layers (Greller \& Drachsler, 2012). This will extend from fine-grained analysis of individual student learning progression aligned to the learning activity and context (Lockyer \& Dawson, 2012) to broader predictions of student learning dispositions (Dawson, Macfadyen, Lockyer, \& Mazzochi-Jones, 2011; Dawson, Tan, \& McWilliam, 2011) and academic success (Fritz, 2011).

A critique of the emerging field of learning analytics can be related to the deficit of research that has been dedicated to curriculum based analytics; that is, the collection, analysis, and interpretation of key stakeholder data throughout multi-year program offerings in order to enhance curriculum development, implementation, and evaluation processes. The ease of access to LMS data alongside increasing institutional pressure to address retention has inadvertently focused learning analytics towards identifying predictors of student performance in preference to a more curriculum centric approach. However, the interpretation of any findings associated with student performance ultimately requires some form of support action. It is this establishment of pedagogical action from learning analytics that requires specific knowledge of the learning context, from which the data was derived (Lockyer \& Dawson, 2012; Lockyer, Heathcote, \& Dawson, 2013). While this seems an obvious statement, the pedagogical context has to date been largely ignored in learning analytic studies. It is only when the visualizations and analyses of results are directly related to the curriculum that the potential for large-scale impact and change can be realized. The results of any evaluation must be transparent and easily accessible for, and interpreted by, all stakeholders in its associated learning and teaching context.

Curriculum analytics can help with the translation of observed patterns into informed action. With a focus on student learning, and drawing on a diverse range of methodological approaches, curriculum analytics provides key stakeholders with access to new modes of learner data and models for interpretation and visualization, as well as fostering a culture of inquiry and scholarship. The incorporation of curriculum analytics, drawing on for instance, social network methodologies, can provide an evaluative and collaborative model to better visualize the relationships that develop between courses leading to the dominant student pathways within a degree program. Furthermore, the analysis of the data with a view towards curriculum evaluation and quality assurance can shed light on issues such as graduation rates, quality of student learning outcomes, employment indicators, strategic development or closure of courses and the outcomes of pre-requisites.

\section{RESULTS: CURRICULUM ANALYTICS AND EVIDENCE-BASED PRACTICE IN A RESEARCH-INTENSIVE UNIVERSITY}

In this preliminary case study we outline how student and curriculum data can begin to be aligned and visualized to promote communication and collaboration within a quality assurance framework. Data was collected from the Faculty of Arts at UBC. The Faculty has in excess of 16000 student FTE in some 30 departments and schools, making it one of the largest faculties in North America. Data was extracted from the University's student information system (SIS), with the extract containing in excess of 1 million records. This 
included information on student enrolment in the Faculty of Arts between the years 2001 and 2010, detailing basic demographics (e.g. age, international, domestic, gender), total course credits for graduation, individual course selections, elected major and minor, as well as the associated grades for all course completions. The records also contained data specifically related to each course offered within the Faculty such as the Department/ School affiliation, class size, average class grade, and the type of course offering (e.g. distance education or on-campus). The project stemmed from a call for greater transparency and communication relating to course choices and progression students experience in their academic journey. It was anticipated that this information would be used to inform and align course-level outcomes with the Faculty's stated graduate attributes.

A curriculum analytics tool was proposed and developed to help visualize and identify the dominant student learning pathways and how these data can begin to inform curriculum decisions for graduate completion rates, student diversity, and alignment with stated graduate outcomes and attributes. The developed in-house tool essentially extracts data from the student information system to establish pathways of student progression (based on course enrolment). The pathways are visualised in a network diagram using JSON (www.json.org). Future development of the software will seek to incorporate additional student and instructor data captured from the institution's learning technologies (e.g. Learning Management System), and standardized evaluations of teaching. It is envisaged that this rich data source will enable the development of learning recommender systems that can generate course suggestions to students based on prior learning experience, identified deficits or areas for improvement in alignment with the graduate goals and outcomes.

The following two diagrams (Figures 1 and 2) collectively represent the concept underlying the tool's development. For instance, Figure 1 illustrates how the tool establishes the basic course network. Students within a program of study have a broad selection of courses available (individual nodes). as students progress through their chosen degree program there is an increasing level of disciplinary specialization, often with a corresponding decrease in class size. This change in class size is reflected in the node size (represented as circles) within the figure. While the relationships (lines linking the nodes) indicate progression from one course to another, there are numerous pathways an individual may choose to undertake. This flexibility of study is only dictated by the program requirements such as the establishment of any stated pre-requisites. For example, a student may have the flexibility to undertake a high-level course without the necessity for any requirements for undertaking the related lower level companion. In contrast to this case study, many of the professional disciplines such as medicine and teacher education, have far reduced options for students to branch outside of an established course pathway.

In representing the "roadmap" of course options it is possible to identify the dominant pathways students elect to undertake. Alternatively, it is also possible to identify instances where students have graduated without undertaking the desired learning experiences (i.e. required courses/ outcomes or assessment were not completed within the student's program of study). The student's selective navigation of courses could be employed to avoid participation in those courses containing activities that are associated with an area of discomfort or perceived weakness or lack of motivation; for example, courses containing statistics, or assessment with oral presentations or group work. The completion of a degree of study where an individual does not experience group work, or alternate com- 


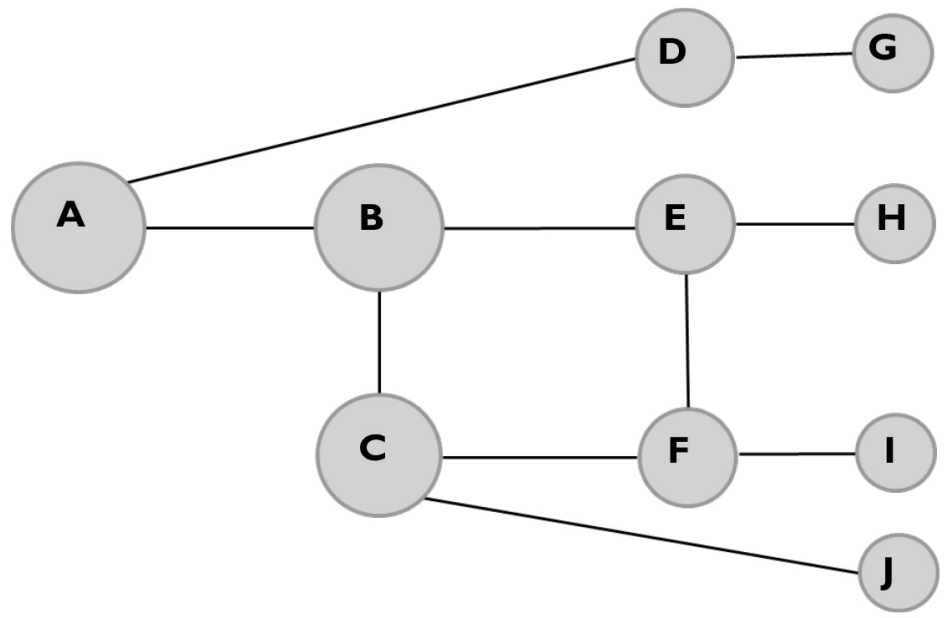

Figure 1. Each node represents a course of study. The lines linking the various courses describe student progression through the program.

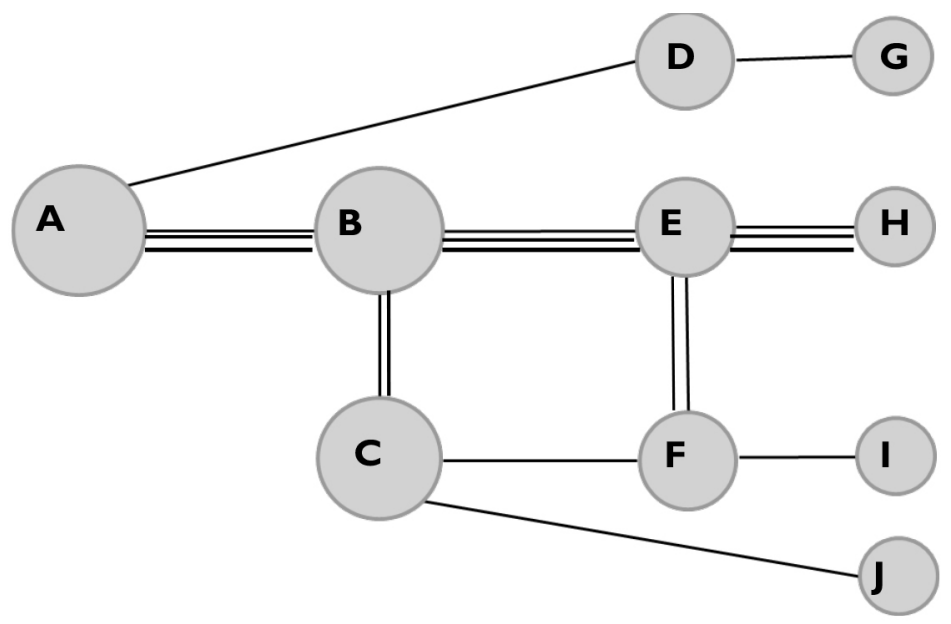

Figure 2. Diagrammatic representation of the dominant pathway through a program of study.

munication methods for example, may not represent the full complement of graduate attributes espoused by the institution. This can present a significant challenge in attempting to assess a student's attainment of institutional and/or program-level graduate attributes.

Building on the previous diagram, Figure 2 illustrates how these dominant pathways can be represented in a network diagram. Each line connecting the nodes represents an individual student and the courses that individual has undertaken in their program of study. Hence, what appears as a "thicker" line indicates a greater number of students undertaking a particular pathway (e.g. A to B to E to H). While Figure 2 simplifies and represents this process as a linear dimension (e.g. course A to B to E to $\mathrm{H}$ ), in actuality students commonly take multiple courses concurrently, and as noted above, not necessarily in a 


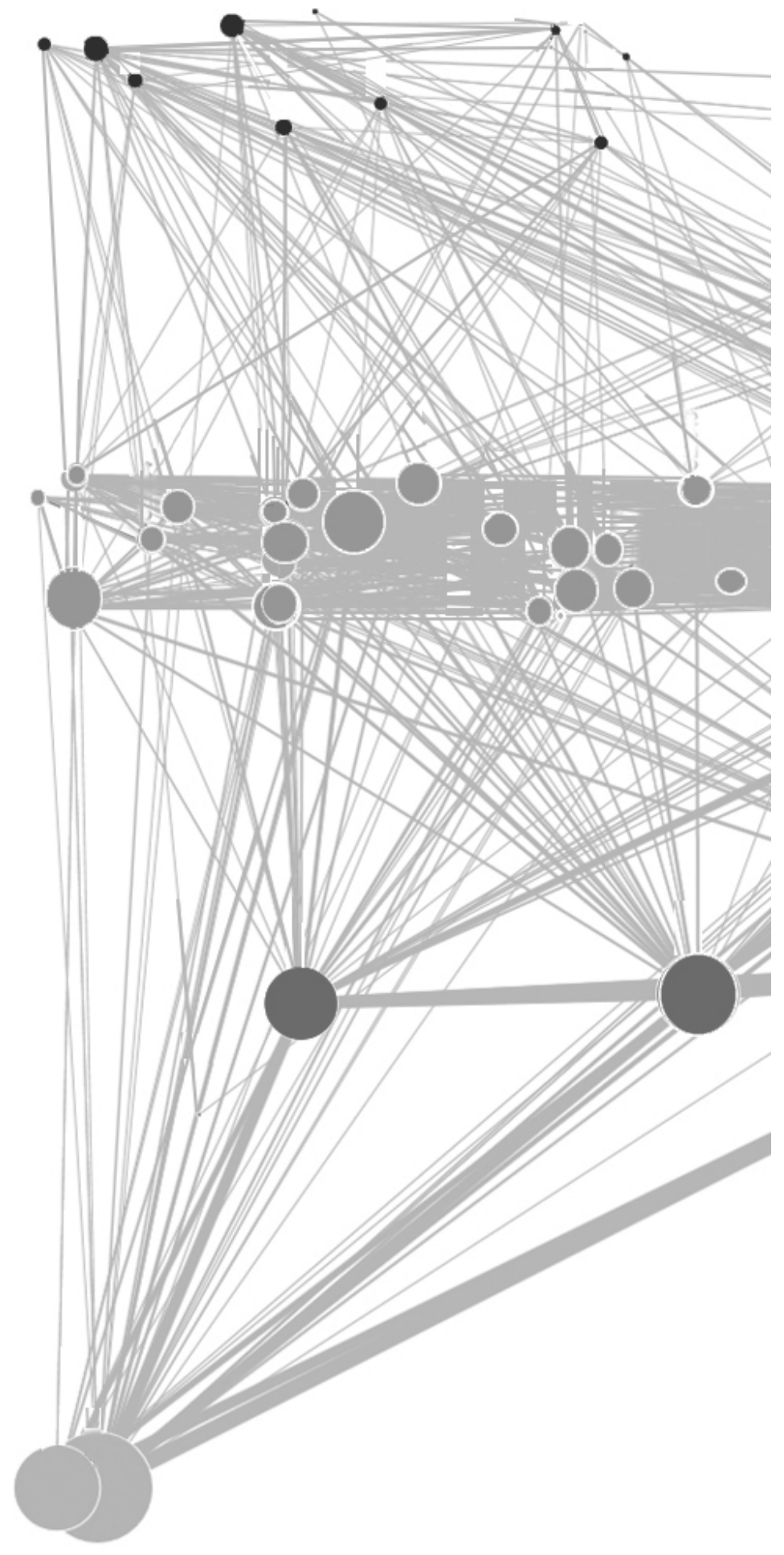

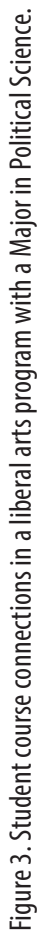


sequential order. Thus, the network diagram can be used to build a visual map that can identify the "dominant" course connections.

While Figures 1 and 2 depicted the underlying principle for developing the course network, Figures 3- 6 demonstrate how this course data (connections) is visualised to inform curriculum practice. Figure 3 is an actual working example of the diversity of courses and opted pathways students undertook for a Major in Political Science in a liberal arts program. The figure illustrates the actual courses (number of students - node size) and the connections formed between courses. For instance, Figure 3 shows two large first year courses (POLI 100 and POLI 101) as represented by the size of the nodes (circles). The subsequent connections (lines) from these courses demonstrate that a student completed, for example Poli100, and also enrolled either concurrently or later in their program of study into an additional course. The aggregation of this data (each individual student and their completed courses) provides a network across a program of study. The greater the number of connections established across courses indicates a popular or dominant pathway of study.

As displayed in Figure 3, the complexity of these diagrams can be overwhelming when attempting to derive any meaningful information. Hence, the tool developed for this case study also included a collection of filtering options to help users develop an understanding of the course connections. The filtering options allow users to rapidly identify differences in student pathways based on selected data comprising the learning analytics suite. For example, the filtering function allows for rapid visualization of any difference in course pathway selections for international or domestic students (Figure 4); high and low performing students or the type of course delivery (distance or on-campus). Figure 5 further illustrates the filtering functionality by highlighting the student composition data for an individual course. For example, data relating to student year level, grades or international and domestic as well as the type of course offering are provided at the course level. Curriculum developers can then gain insight into any differences in courses or outcomes undertaken by a specific student cohort (e.g. international vs domestic). Similarly, instructors could adjust their curriculum design based on the predicted composition of the student body (e.g. a high percentage of commencing students for a second level course). In essence, as student demographics, course learning outcomes and assessment are increasingly documented and captured for quality assurance processes, these data can be incorporated into the system to provide further detailed curriculum information to all teaching faculty.

When comparing the network model to a quality assurance framework, the data can be used to assess how the individual course learning experiences collectively align with the program-level outcomes. For example, an intended program outcome may relate to the demonstration of effective oral presentation skills or teamwork. The network representation could be adopted to highlight where these required outcomes have been addressed and to what level of proficiency alongside any associated assessment. To review the alignment between the stated Faculty graduate attributes and course learning outcomes, individual students or an identified population can be traced through the network to audit their degree pathway. This audit is accessed against the specific rules and requirements necessary for graduation in the program as well as alignment against the learning, skills and attributes developed as a result of the individual's course selection. 

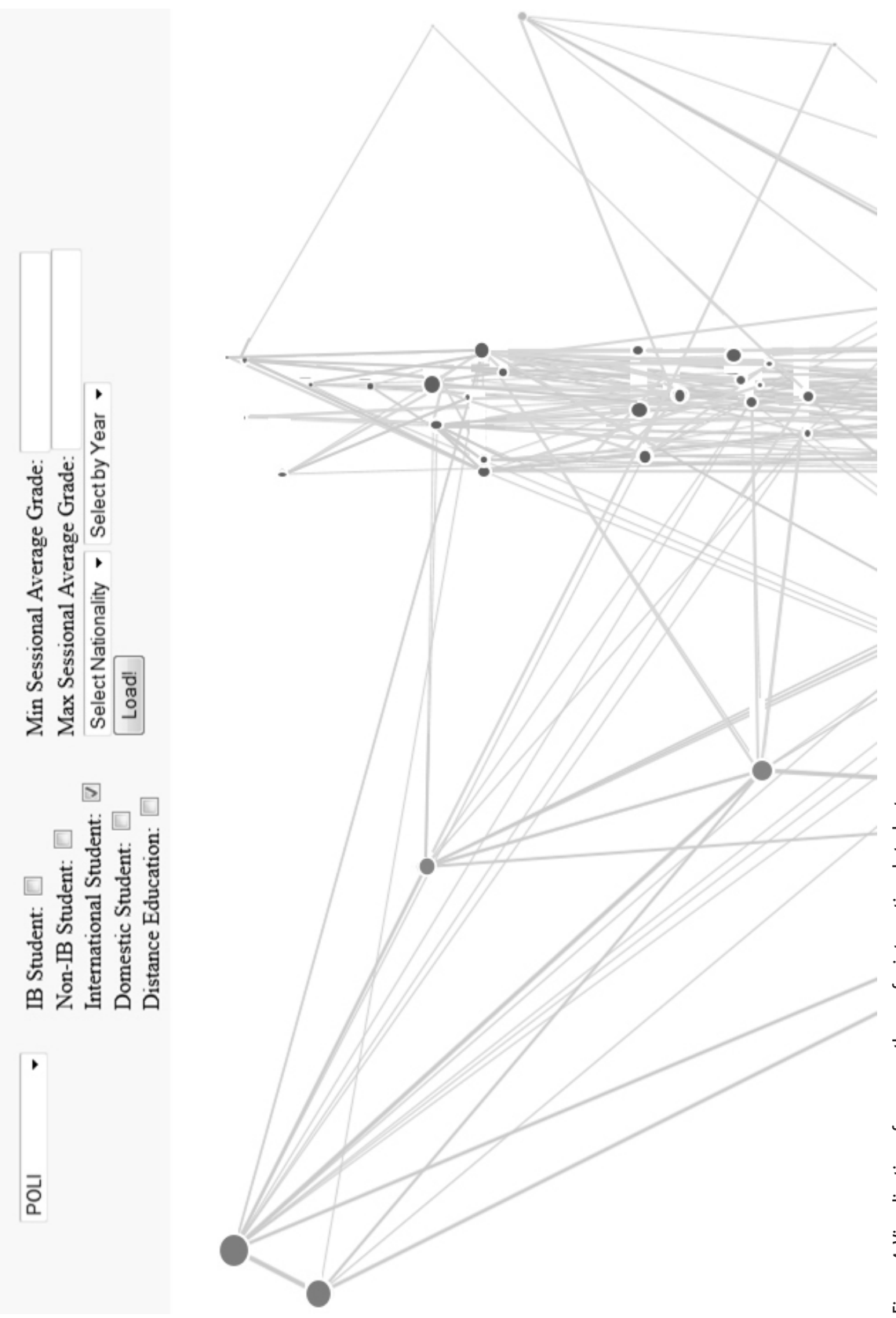

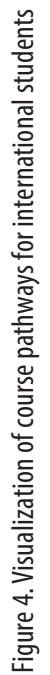



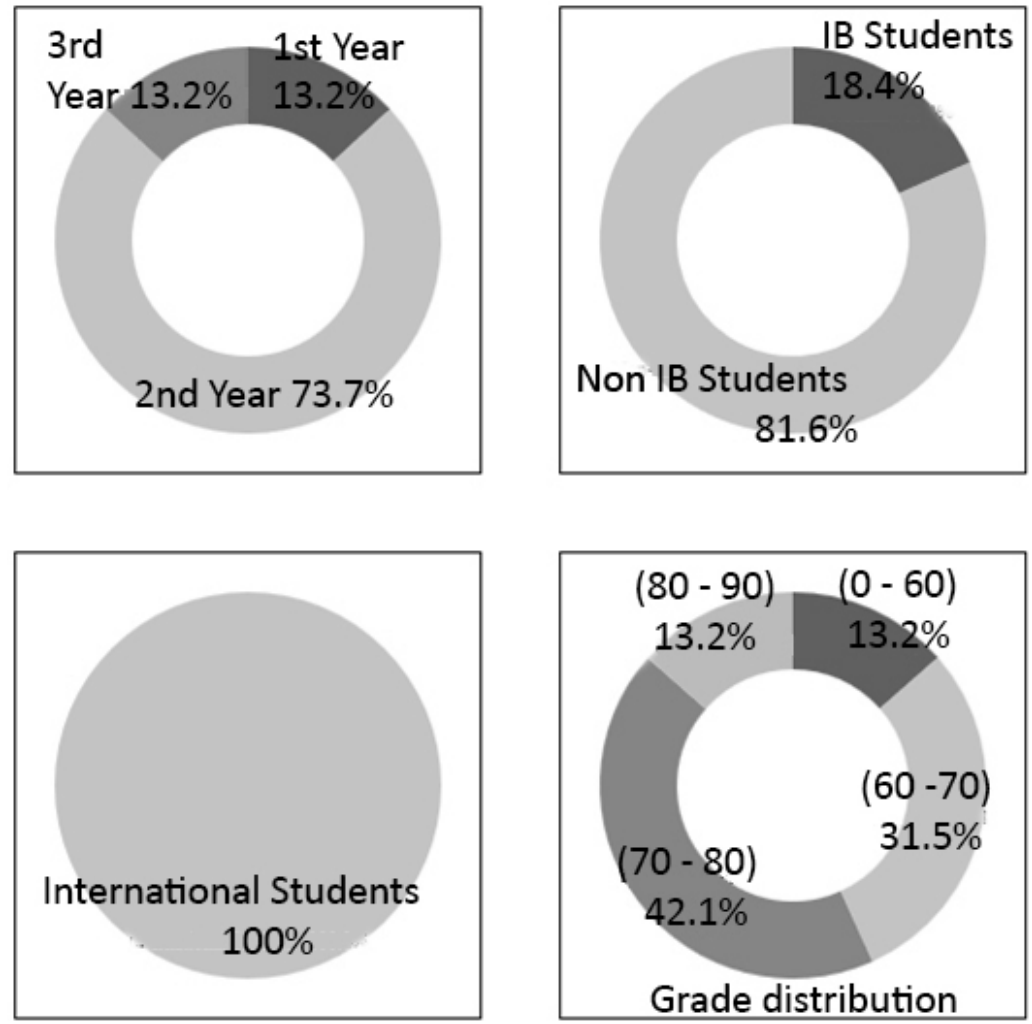

Figure 5. Visualization of course level data

The incorporation of this more fine-grained level of data would require faculty to undertake an initial curriculum mapping exercise. Once this data has been collected there is an opportunity to incorporate metadata and other signifiers into the software in terms of filtering functions to aid visualizations and analyses.

To evaluate the potential of the course network process, an initial pilot was undertaken within the Department of Political Science. The curriculum mapping exercise identified the specific course learning outcomes, learning design, and assessment practices associated with Political Science courses. The analysis of the learner data and pathways also informed questions regarding the timely completion of graduates enrolled in the Political Science major.

\section{GRADUATION RATES}

Timely program completion is a growing concern among higher education managers and administrators. This is, in part, due to an increasing trend for government education policy to relate institutional funding with evidence of graduate completion. This places pressure on institutions to not only provide (and demonstrate) a quality learning and teaching experience but to ensure timely progression to graduation. Students who do not complete in a timely manner result in an increased cost to the institution. These noted financial pressures associated with growing accountability concerns motivated an exami- 
nation of the curriculum pathways a student undertakes that contribute to, or impede, a student's timely completion. The visualizations generated by the curriculum network tool prompted discussions among senior management around course completions and graduation rates. The Department of Political Science was used as an initial starting point given this Department was already engaged in a revision of its program curriculum. Using the curriculum network tool, data was extracted from the SIS and analysed for course completion rates (number of credits) and time to graduation.

Between the years 2001 and 2007, more 2400 students declared a major in Political Science at UBC. However, within this population 24 percent of students graduated in excess of the required credits (120) necessary for degree completion. Examination of those students with 150 credits or more suggests these students undertake a high number of third- and second-year courses in comparison with their more timely peers. A possible explanation for this anomaly lies in the network diagram (Figure 6). For completion of the degree program it is required that students undertake a fourth-year specialization in their chosen major discipline. However, as these class sizes are generally small (indicated by size of the node in the fourth year courses - Figure 6), there is much competition for placements among the cohort. Competition in this instance is based on prior GPA, whereby students with higher grades (top 90th percentile) have first selection of the available courses. Selection for the remainder of the cohort is on a first-come-firstserved basis. It is hypothesized that students with a high number of credits were not able to enrol in their desired fourth-year course and, therefore, undertook further study in alternate lower level options until such an opportunity arose to complete the identified fourth-year course. This issue is further amplified through the high number of individual courses available in the third year in comparison to the fourth year (Figure 6). A simple bivariate correlation (pearson's $r$ ) confirms the presence of a weak yet significant negative relationship between accumulated credits and grades $(r=0.21, p<0.01 \mathrm{n}=2411)$. Simply put, the higher the number of credits obtained in the degree program, the lower the student's overall GPA.

Learning analytics becomes most impactful when data is used to empower both instructor and student. The learning analytics data illustrates how an instructor can begin to drill down into the finer grained details of the courses to obtain better insight into the types of learning experiences and assessment types their students have undertaken. This information can be used to identify students' with a particular assessment model such as group work, research writing, etc. As such, there is a clear visualisation of the curriculum relationships that have been established between courses (inter and intra-disciplinary) that can, in turn, inform the types and level of learning activities an instructor could design and implement.

This is an initial case study, and the developed software has identified that meaningful curriculum insights into a program of study can be quickly derived in an automated manner. These insights can be used to better inform the development of curriculum activities. However, while there is much potential in the generation of these forms of curriculum analytics, any implementation must also consider the accuracy and authenticity of data that is extracted and collected. The next challenge is to identify how these forms of visualisations can be embedded into course level curriculum analytics in order to assist curriculum planning teams with the strategic implementation of responsive course 

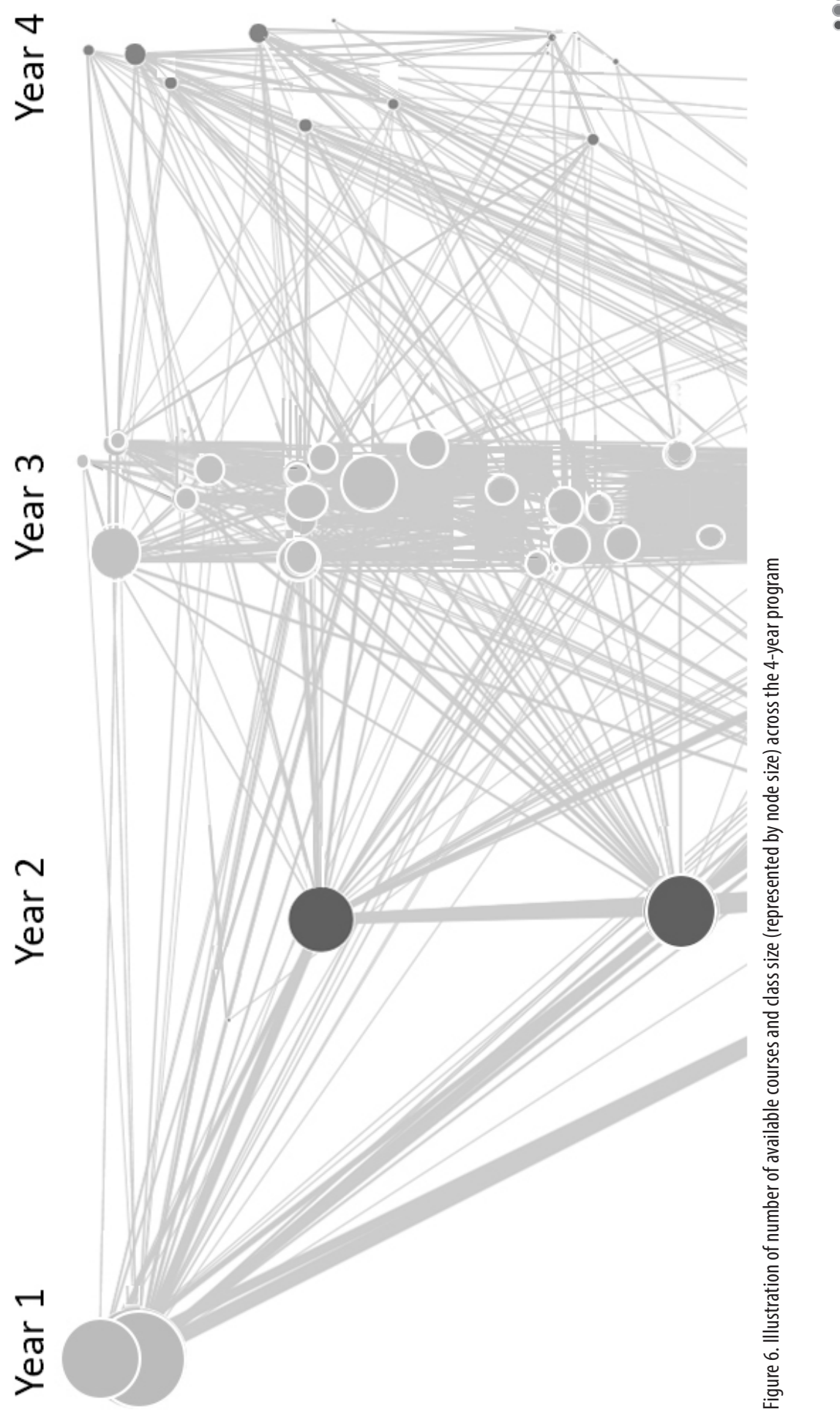

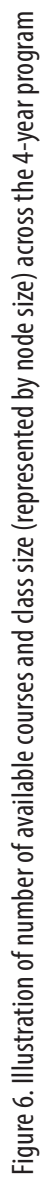


offerings, the design of learning activities, and the evaluation of teaching practices in a proactive and time efficient process.

\section{LIMITATIONS}

The study of curriculum and social networks is a complex process that is obviously influenced by numerous factors. For instance, to understand how the derived quantitative data relates to the design and context of the teaching and learning activities requires a rigorous qualitative approach. The reliance on quantitative data must be aligned to the specific context for subsequent interpretation into action. As such, the extraction of these forms of data in isolation of the more qualitative insights limits the broader generalizability of the study. The extraction of data relating to course networks and graduation rates within one program of study further limits the generalizability of the findings. However, an aim of this study was to first establish a method for informing curriculum development that was both scalable and potentially automated. While recognising the inherent limitations in quantitative methods, the extraction of these forms of data can provide sound indicators for progressing curriculum reform and renewal that is both strategic and empirical.

\section{CONCLUSION}

This paper is a reflective examination of the use of curriculum analytics by drawing on social network methodologies for assessing and visualizing the integration and linkages across individual courses that ultimately form a student's complete program of study in the Faculty of Arts at a large Canadian research-intensive university. Using curriculum analytics in this context, we were able to rapidly visualize common course pathways associated with a program of study and to refine these results based on various student demographics. The software has much potential for comparative analysis of curriculum pathways leading to student satisfaction, sense of community, employability, and academic success. Furthermore, the novel software can be applied in a more quality assurance process to demonstrate alignment with the institution's stated graduate attributes alongside any skills and requirements linked to professional accrediting bodies.

Emerging technology-enabled inquiry methods such as curriculum analytics have enormous potential to inform evidence-based practice and curriculum renewal strategies in complex, multifaceted and inherently situated undergraduate and graduate degree program settings. Curriculum analytics can assist in establishing a culture of inquiry and scholarship about continuous program improvements. While the novel curriculum analytic processes outlined in this paper show much promise, the research in this area is in the early stages of implementation. Further investigation is required to interrogate how such analytics impact on individual, departmental and institutional approaches to curriculum reform. Although there are many challenges and areas for improvement, early indications of the use of curriculum analytics are testimony to their increasing current and potential value for curriculum leaders and their respective communities of practice in a research-intensive university environment.

Shane Dawson is Associate Professor (Technology Enhanced Learning) and Director of the Learning and Teaching Unit at the University of South Australia.

Harry Hubball is a Professor and Academic Program Director for the International Faculty SoTL Leadership Program at The University of British Columbia, Canada. 
1. Purdue University Course Signals: http://www.itap.purdue.edu/learning/tools/signals/

\section{REFERENCES}

Arnold, K.E. (2010). Signals: Applying Academic Analytics. EDUCAUSE Quarterly Magazine, 33(1). http://www.educause.edu/EDUCAUSE+Quarterly/EDUCAUSEQuarterlyMagazineVolum /SignalsApplyingAcademicAnalyti/199385

Bernhard, A. (2012). Quality Assurance in an International Higher Education Area: A case study approach and comparitive analysis. Germany: VS Verlag für Sozialwissenschaften.

Bryk, A.S., Gomez, L.M., Grunow, A., \& Bryk, A. S. (2011). Getting ideas into action: Building networked improvement communities in education. In M. Hallinan (Ed.), Frontiers in sociology of education (pp. 127-162). Dordrecht, the Netherlands: Verlag.

Coates, H. (2005). The value of student engagement for higher education quality assurance. Quality in Higher Education, 11(1), 25-36.

Dawson, S. (2010). 'Seeing' the learning community: An exploration of the development of a resource for monitoring online student networking. British Journal of Educational Technology, 41(5), 736-752.

Dawson, S., Macfadyen, L., \& Lockyer, L. (2009). Learning or performance: Predicting drivers of student motivation. Paper presented at the Same places, different spaces. Proceedings ascilite 2009., Auckland, NZ.

Dawson, S., Macfadyen, L., Lockyer, L., \& Mazzochi-Jones, D. (2011). Using social network metrics to assess the effectiveness of broad based admission practices. Australasian Journal of Educational Technology, 27(1), 16-27.

Dawson, S., Tan, J. P. L., \& McWilliam, E. (2011). Measuring creative potential: Using social network analysis to monitor a learners' creative capacity. , 27(6), 924-942. Australasian Journal of Educational Technology, 27(6), 924-942.

Duval, E. (2011, February, 2011). Attention please! Learning analytics for visualization and recommendation. Paper presented at the Proceedings of 1st International Conference on Learning Analytics and Knowledge, Banff, Canada.

Ferguson, R. (2012). Learning analytics: Drivers, developments and challenges. International Journal of Technology Enhanced Learning, 4(5/6), 304-317.

Fraser, S.P. (2006). Shaping the University curriculum thorugh partnerships and critical conversations. International Journal for Academic Development, 11(1), 5-17.

Friedman, V.J. (2008). Action science: Creating communities of inquiry in communities of practice. In P. Reason \& H. Bradbury (Eds.), Handbook of action research: The concise paperback edition (pp. 131-143). Thousand Oaks, CA: Sage Publications.

Fritz, J. (2011). Classroom walls that talk: Using online course activity data of successful students to raise self-awareness of underperforming peers. The Internet and Higher Education, 14(2), 89-97.

Greller, W., \& Drachsler, H. (2012). Translating learning into numbers: A generic framework for leanring analytics. Educational Technology \& Society, 15(3), $42-57$.

Hubball, H.T., \& Burt, H. (2004). An integrated approach to developing and implementing learning-centred curricula. International Journal for Academic Development, 9(1), 51-65. 
Hubball, H.T., Lamberson, M., \& Kindler, A. (2012). Strategic Restructuring of a Centre for Teaching and Learning in a Research-Intensive University: Institutional Engagement in Scholarly Approaches to Curriculum Renewal and Pedagogical Practices. International Journal for University Teaching and Faculty Development, 3(2).

Hubball, H.T., Pearson, M., \& Clarke, A. (2013). SoTL inquiry in broader curricula and institutional contexts: Theoretical underpinnings and emerging trends. International Journal for Inquiry in Teaching and Learning and Instruction, 1(1).

Jessop, T., McNab, N., \& Gubby, L. (2012). Mind the gap: An analysis of how quality assurance processes influence programme assessment patterns. Active Learning in Higher Education, 13(2), 143-154.

Lockyer, L., \& Dawson, S. (2012). Where learning analytics meets learning design. Paper presented at the Proceedings of the 2 nd International Conference on Learning Analytics and Knowledge, Vancouver, British Columbia, Canada.

Lockyer, L., Heathcote, E., \& Dawson, S. (2013). Informing Pedagogical Action: Aligning Learning Analytics With Learning Design. American Behavioral Scientist, 57(10), 1439-1459.

Macfadyen, L., \& Dawson, S. (2010). Mining LMS data to develop an "early warning system" for educators: A proof of concept. Computers \& Education, 54(2), 588-599.

Marginson, S. (2008). The global position of Australian higher education to 2020. Melbourne, Australia: Centre for the Study of Higher Education (CSHE), University of Melbourne.

Marshall, Stephen J., Orrell, Janice, Cameron, Alison, Bosanquet, Agnes, \& Thomas, Sue. (2011). Leading and managing learning and teaching in higher education. Higher Education Research \& Development, 30(2), 87-103. doi: 10.1080/07294360.2010.512631

Neary, M. (2003). Curriculum models concepts and research Curriculum studies in postcompulsory and adult education: a teachers and student teachers study guide. Cheltenham, UK: Nelson.

Norris, D., Baer, L., Leonard, J., Pugliese, L., \& Lefrere, P. (2008). Action analytics: Measuring and improving performance that matters in higher education. EDUCAUSE Review, 43(1), 42-67.

O'Neill, G. (2010). Initiating curriculum revision: exploring the practices of educational developers. International Journal for Academic Development, 15(1), 61-71.

Pearson, M., \& Hubball, H.T. (2012). Scholarly approaches to curricular integration: Theorypractice implications for the Health Professions. American Journal for Pharmaceutical Sciences Education, 76(10), Article 204.

Siemens, G., \& Baker, R. (2012). Learning analytics and educational data mining: towards communication and collaboration. Paper presented at the Proceedings of the 2 nd International Conference on Learning Analytics and Knowledge, Vancouver, British Columbia, Canada.

Skolnick, M. . (2010). Quality assurance in higher education as a political process. Higher Education Management and Policy, 22(1), 67-86.

Wagner, E., \& Ice, P. (2012). Data changes everything: Delivering on the promise of learning analytics in higher education. Educause Review, 47(4), 33-42. 